\title{
Uterine inversion during caesarean section: a case report
}

\author{
Anjaly Raj, Kallol Kumar Roy, Rinchen Zangmo*, Anshu Yadav, \\ Nilofar Noor, Sushmita Saha, Sonam Bairwa
}

Department of Obstetrics and Gynaecology, All India Institute of Medical Sciences, New Delhi, India

Received: 21 August 2020

Accepted: 30 September 2020

\section{*Correspondence:}

Dr. Rinchen Zangmo,

E-mail: rinchhen.zn@gmail.com

Copyright: (c) the author(s), publisher and licensee Medip Academy. This is an open-access article distributed under the terms of the Creative Commons Attribution Non-Commercial License, which permits unrestricted non-commercial use, distribution, and reproduction in any medium, provided the original work is properly cited.

\begin{abstract}
The present report aim to sensitise the obstetrician regarding risk of uterine inversion in a scarred uterus and the importance of immediate manual replacement. Represented case is of 40 years gravida five with previous one spontaneous abortion and previous history of three ectopic pregnancies with history of open left salpingectomy for ruptured left tubal ectopic pregnancy and history of laparoscopic right tubal clipping and uterine rupture repair for cornual pregnancy underwent an emergency caesarean section at 34 weeks. Since there were no signs of placental separation, controlled cord traction of placenta was attempted and uterine inversion was noticed. Manual replacement of uterus was done followed by manual removal of the adherent placenta. There was no postpartum haemorrhage. Inversion of uterus during caesarean section is a rare obstetric complication. If unrecognized it could lead to serious morbidity due to haemorrhage and shock. Prompt diagnosis and repositioning of the uterus are important measures in management.
\end{abstract}

Keywords: Uterine inversion, Caesarean section, Adherent placenta, Scarred uterus

\section{INTRODUCTION}

Inversion of uterus is a life threatening obstetric emergency. It requires immediate identification and correction. If unrecognized severe haemorrhage and shock can lead to maternal death. Manual replacement of the uterus should be attempted at the earliest. Uterine inversion through caesarean incision is a rare obstetric incident. In a review done by Baskett TF over a 24 year period between 1977 to 2000, the incidence of acute uterine inversion following vaginal birth was one in 3737 , and following caesarean section, in $1860 .{ }^{1}$ Delay in re-inversion may be associated with hypotension and attempts should be made to reinvert the uterus with the placenta still attached if placental separation has not occurred. ${ }^{2}$ One such case of uterine inversion with attached placenta is being reported.

\section{CASE REPORT}

40 years gravida five with previous one spontaneous abortion and previous history of three ectopic pregnancies conceived by in vitro fertilisation (IVF) with donor oocyte, with twin gestation reduced to singleton by selective fetal reduction in the first trimester diagnosed with gestational diabetes mellitus controlled on insulin along with metformin and intrahepatic cholestasis of pregnancy was booked in our hospital for antenatal care. Prior to this pregnancy, IVF conception was attempted thrice which did not have successful outcomes. 18 years ago, she underwent laparotomy followed by left salpingectomy for ruptured left tubal ectopic pregnancy. She also had an unruptured right tubal ectopic pregnancy which was medically managed 17 years back and history of laparoscopic right tubal clipping and uterine rupture repair for cornual pregnancy two years back. She has undergone diagnostic laparoscopy and hysteroscopy prior 
to IVF and has taken anti-tuberculosis medication for genital tuberculosis in the past.

An emergency lower segment caesarean section had to be done at 34 weeks in view of preterm labour. The caesarean section was done under spinal anaesthesia. Fetus was in breech presentation. Breech extraction was done uneventfully. Delivery of placenta by controlled cord traction was attempted as a gush of blood was visible indicating the placental separation.. While traction was being applied, uterine inversion was noticed with a part of the placenta remaining attached to the uterus (Figure 1).

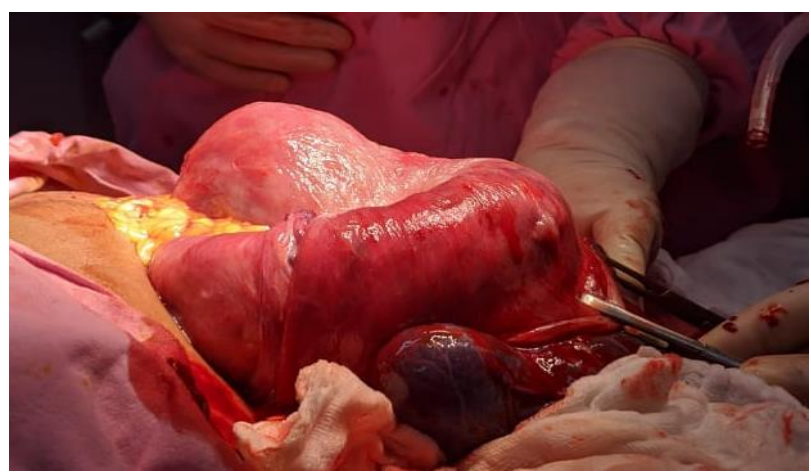

Figure 1: Uterus inverted through the caesarean incision with attached placenta.

Immediately, oxytocin infusion was discontinued and manual replacement of the inverted uterus was attempted with the placenta retaining its attachment to the uterus. Pressure was applied with a fist of the hand over the inverted fundus while the everted upper edge of the incision was brought down and inversion was corrected (Figure 2). After repositioning the uterus, uterine massage was done. Oxytocin infusion was restarted. On examination it was noticed that placenta was adhered to the right cornual side of the uterus at the site of previous rupture repair. Manual removal of placenta was done uneventfully. Placenta and membranes were examined and were found to be complete. Haemostasis was ensured and uterus was well contracted with no active bleeding from the cavity. Uterus was closed in two layers.

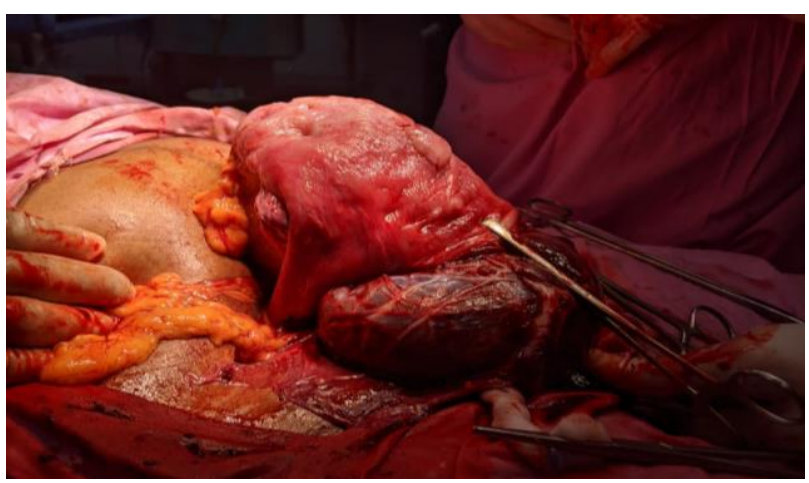

Figure 2: Uterus after repositioning by manual replacement with attached placenta.
Vitals remained stable throughout the surgery. There was no postpartum haemorrhage. Postoperative period was uneventful. Both the patient and her baby were discharged in stable conditions on the fifth day of the caesarean section.

\section{DISCUSSION}

Uterine inversion during caesarean section is a rare complication in obstetrics. The exact incidence is unknown but only a few cases have been reported in literature.

Fundal insertion of placenta, short cord inherent weakness of uterine musculature, intravenous bolus oxytocic agent, adherent placenta attempts at manual removal of retained placenta are some of the major causes. $^{2-9}$ In our case it could have been the weakness of uterine musculature along with fundal insertion of placenta, adherent placenta and cord traction which caused the uterine inversion.

Haemorrhage, shock and pain are cardinal features found in a case of uterine inversion. Pain might not be appreciated in inversion in a caesarean section. ${ }^{3}$ Shock is often out of proportion to the blood loss. The possible mechanisms of shock include haemorrhage, stretching of the broad ligaments and peritoneum, and ovarian compression. $^{2}$ Neurologic element of shock is eliminated since during caesarean section patient is under general or regional anaesthesia. ${ }^{3}$ Hence the haemorrhage remains the main cause of shock in uterine inversion during caesarean section. The inversion reversion interval determines the amount of blood loss. ${ }^{5,9,10}$ In this case prompt diagnosis and immediate manual replacement resulted in a successful outcome. It has often been found that blood loss in uterine inversion at caesarean section is less when compared to inversion through the vagina. ${ }^{2,11}$

Vavilis et al report a case of complete uterine inversion during caesarean section in an elective caesareans section done under general anaesthesia, inversion could not be initially reduced despite of multiple attempts, finally they had to deepen sevoflurane anaesthesia from $1 \%$ to $5 \%$ to make the reversion possible. ${ }^{4}$ Post-operative course of the patient was uneventful.

There have been reports of cardiac arrest following uterine inversion in caesarean section. High spinal block; vagal stimulation caused by uterine inversion; effect of oxytocin; anaphylactic reaction to antibiotics; or embolism (venous thromboembolism, air or amniotic fluid embolism) in addition to massive haemorrhage are the possible causes of cardiac arrest. ${ }^{9,12 .}$

It might be difficult to identify anatomy in an inverted uterus and hence can lead to a delay in diagnosis. Delay in diagnosis and correction can cause haemorrhage and reduce the chances of successful manual replacement of uterus. 
In an awake patient undergoing caesarean section under regional anaesthesia, uterine relaxation may be brought about with tocolytics like terbutaline or ritodrine which can aid manual replacement. ${ }^{2}$ Bakri balloon has also been used to control haemorrhage and reduce the possible risk of immediate recurrent inversion. ${ }^{13}$

\section{CONCLUSION}

In conclusion, uterine inversion is a life threatening complication. High degree of suspicion, early identification and immediate manual replacement play a key role in management.

\section{ACKNOWLEDGMENTS}

The authors acknowledge the residents and staff of the department of obstetrics and gynaecology, All India Institute of Medical Sciences, Delhi for their support.

Funding: No funding sources Conflict of interest: None declared

Ethical approval: Not required

\section{REFERENCES}

1. Baskett TF. Acute uterine inversion: a review of 40 cases. J Obstet Gynaecol Can. 2002;24(12):953-6.

2. Emmott RS, Bennett A. Acute inversion of the uterus at Caesarean section. Anaesthesia 1988; 43:118-20.

3. Banerjee N, Deka D, Roy KK, Takkar D. Inversion of uterus during caesarean section. Eur J Obstet Gynecol Reprod Biol. 200; 91:75-7.

4. Vavilis D, Tsolakidis D, Athanatos D, Goutzioulis A, Bontis JN. Complete uterine inversion during caesarean section: A case report. Cases J. 2008; 1(1):127.

5. Rudloff U, Joels LA, Marshall N. Inversion of the uterus at caesarean section. Arch Gynecol Obstet. 2004;269(3):224-6.
6. Terp MR, Rasmussen KL. Uterine inversion during cesarean section. Acta Obstet Gynecol Scand. 1998; 77:788-9.

7. Tsivos D, Malik F, Arambage K, Hagan P, Lee C. A life threatening uterine inversion and massive postpartum haemorrhage caused by placenta accrete during Caesarean section in a primigravida: a case report. Cases J. 2009;2(1):138.

8. Rezende J, Barcellos JM. Inversão uterina em cesárea. Placenta accreta Uterine inversion in cesarean section. Rev Ginecol Obstet (Sao Paulo). 1965;117(1):38-45.

9. Khalil A, Raafat A, Calleja-Agius J, Bell R, O'Brien P. Cardiac arrest associated with uterine inversion during caesarean section. J Obstet Gynaecol. 2006; 26(7):696-7.

10. Studziński Z, Branicka D. Acute complete uterine inversion-care report. Ginekol Pol. 2001; 72(11): 881-4.

11. Masters AP. Acute inversion of the uterus at caesarean section. Anaesthesia. 1989; 44(2):167-8.

12. Marshall NB, Catling S. Cardiac arrest due to uterine inversion during caesarean section. Int $\mathrm{J}$ Obstet Anesth. 2010;19(2):231-4.

13. Vivanti AJ, Furet E, Nizard J. Successful use of a bakri tamponade balloon in the treatment of puerperal uterine inversion during caesarean section. J Gynecol Obstet Hum Reprod. 2017; 46(1):101-2.

Cite this article as: Raj A, Roy KK, Zangmo R, Yadav A, Noor N, Saha S, et al. Uterine inversion during caesarean section: a case report. Int J Reprod Contracept Obstet Gynecol 2020;9:4744-6. 